\title{
Access to novel therapies for COVID-19 - distributive justice and Russian roulette?
}

In an ideal world, universal access to healthcare should be achievable; all COVID-19 patients should have access to therapies that improve outcomes. These include existing, repurposed and novel therapies. Novel therapies need to be safe and effective, and a well-established path for obtaining information regarding safety and efficacy has been in place for many years. The pandemic has seen an acceleration in these processes: existing medicines are being rapidly repurposed, there is a massive drive to develop novel treatments and vaccines, and access to experimental treatments is being granted on compassionate grounds.

The management of COVID-19 has evolved rapidly, for a disease that we have known for less than a year. Invasive ventilation for critically ill patients dominated the headlines in the early days of the pandemic, and massive drives were initiated to manufacture more ventilators. Several antimicrobial medications, notably for Ebola (remdesivir), HIV (lopinavir/ritonavir), malaria (chloroquine/ hydroxychloroquine) and bacterial respiratory infections (azithromycin) have been repurposed in an attempt to reduce viral load in the early stages of the disease. With an increased understanding of the pathogenesis of COVID-19 has come the recognition that many of the consequences of SARS-CoV-2 infection are the result of the body's response to the virus rather than the virus itself. Multi-organ involvement is the consequence of systemic hyperinflammation and a state of hypercoagulation and occurs as viral load decreases. Ironically, in the midst of efforts to identify novel approaches to management, we appear to be relying on those that are tried and tested: oxygen administration via non-invasive means, dexamethasone and other corticosteroids for inflammation, and anticoagulants to prevent thrombosis.

The reasons for the emergence of extremes in behaviour during the pandemic are multiple and complex, not the least of which are political and economic. Coinciding with the pandemic has been the build-up to the US presidential election, in which COVID19 has featured prominently. With the USA having the highest number of deaths globally and one of the highest percentages of total population affected, strong opinions have been voiced and criticisms have abounded. It is not the purpose of this editorial to provide an opinion or to add to the chorus of experts; suffice it to note that social media and television have provided access to highly granular and deeply personal information on everyone concerned, and this has impacted on public opinion and readiness to adhere to guidance.

Conflicting views, changes in opinion, the emergence of alternative theories and proponents of the 'deep state' have added further to the confusion and have undermined the trust of the general public. Much of this behaviour has had an impact on access to therapies for COVID-19, or is threatening to do so. Hoarding of medicines such as remdesivir and ongoing discussions about access to vaccines are two cases in point. This situation has been aggravated by the so-called 'infodemic', a phrase coined in 2003 and recently used by the World Health Organization (WHO ${ }^{[1]}$ to describe the unprecedented deluge of information to which the global population has been subjected. Suspicion abounds regarding efforts to promote the use of non-pharmacological interventions, as well as existing and novel therapies, and the anti-vaxxer movement has gained momentum.
The world reacted strongly to the news that President Donald Trump had COVID-19, and a number of critical issues were brought to the fore. The one that stands out in the context of this editorial relates to access to novel and potentially curative medicines. Human life cannot be quantified in monetary terms, and it is likewise not possible to place a higher value on one life over another. Universal health coverage as defined by the WHO means that 'all people and communities can use the promotive, preventive, curative, rehabilitative and palliative health services they need, of sufficient quality to be effective, while also ensuring that the use of these services does not expose the user to financial hardship. ${ }^{[2]}$ In practice however, it appears that access to and quality of healthcare are directly proportional to socioeconomic status, and quality of healthcare is adversely affected in a resourcepoor setting.

The universal right to healthcare is based on the philosophical notion of distributive justice, which advocates for a just allocation/ distribution of goods among members of society. COVID-19 has highlighted the ever-widening gap between the wealthy and the poor. One way of reducing this gap could be to include a representative cross-section of the entire population in clinical trials for experimental treatments, and not to favour one group or individual over another.

How much evidence is required before an experimental treatment can be administered with an acceptable degree of safety? A case in point is convalescent plasma, which appears to be safe but for which there is so far insufficient efficacy data to support its use on a large scale. One of the active components is believed to be neutralising antibodies to SARS-CoV-2. Could the administration of these antibodies on their own suffice? President Trump's physicians believed this to be the case, and recently treated him with a cocktail of neutralising antibodies, REGN-COV2, manufactured by Regeneron. ${ }^{[3]}$ Although this drug has been shown to reduce viral load in non-hospitalised patients, and entered phase III clinical trials in July, questions regarding sustainability and long-term effects cannot be answered in such a short space of time. Equally important is the fact that the US President's treatment also included remdesivir, dexamethasone, supplemental oxygen, zinc, vitamin $\mathrm{D}$, famatodine, melatonin and aspirin; ${ }^{[4]}$ the consequences of administering this combination are not known. It is still early days in President Trump's illness (at the time of writing, 7 October 2020), and the emergence of a very real category of so-called 'long-haulers', people who experience symptoms over a long period as a consequence of SARS-CoV-2 infection, may become important over time.

One might ask: what motivated the choice of this treatment approach? This is not the forum to attempt to answer this question; suffice it to say that an element of calculated risk is likely to have been involved. Were the President and his physicians playing Russian roulette? The stakes could not be higher, given that election day is less than a month away.

2020 is likely to remain one of the most tumultuous and disruptive years in history. It has taught us that we need to rely on science and avoid being misled by dubious 'facts' that are disguised as scientific evidence. In times like these, it is useful to recall the words of Rudyard Kipling's inspirational poem 'If' (1895) (I am sure that the last line of the poem would have reflected greater sensitivity to gender equality had he written this in 2020): 
If you can keep your head when all about you Are losing theirs and blaming it on you, If you can trust yourself when all men doubt you, But make allowance for their doubting too; If you can wait and not be tired by waiting, Or being lied about, don't deal in lies, Or being hated, don't give way to hating, And yet don't look too good, nor talk too wise: If you can dream - and not make dreams your master, If you can think - and not make thoughts your aim; If you can meet with Triumph and Disaster And treat those two impostors just the same; If you can bear to hear the truth you've spoken Twisted by knaves to make a trap for fools, Or watch the things you gave your life to, broken, And stoop and build 'em up with worn-out tools: If you can make one heap of all your winnings And risk it all on one turn of pitch-and-toss, And lose, and start again at your beginnings And never breathe a word about your loss; If you can force your heart and nerve and sinew To serve your turn long after they are gone, And so hold on when there is nothing in you Except the Will which says to them: 'Hold on!' If you can talk with crowds and keep your virtue, Or walk with kings - nor lose the common touch,
If neither foes nor loving friends can hurt you, If all men count with you, but none too much; If you can fill the unforgiving minute With sixty seconds' worth of distance run, Yours is the Earth and everything that's in it, And - which is more - you'll be a Man, my son!

\author{
Michael S Pepper \\ Institute for Cellular and Molecular Medicine, Department of \\ Immunology; and SAMRC Extramural Unit for Stem Cell Research \\ and Therapy, Faculty of Health Sciences, University of Pretoria, \\ South Africa \\ michael.pepper@up.ac.za
}

1. World Health Organization. Working together to tackle the 'infodemic'. https://www.euro.who.int/ en/health-topics/Health-systems/digital-health/news/news/2020/6/working-together-to-tackle-theinfodemic (accessed 12 October 2020).

2. World Health Organization. Universal health coverage and health financing. http://www.who.int/

health_financing/universal_coverage_definition/en/(accessed 7 October 2020).
3. La Monica PR. Trump has ties to drugmaker Regeneron - and now its stock is surging. CNN Business, 5 October 2020. https://edition.cnn.com/2020/10/05/investing/trump-regeneron/
. Business, 5 October 2020 . https://edition.cnn.com $/ 2020 / 10 / 05 /$ investing/trump-regeneron/
index.html?utm_term $=1601984100992294$ cebd278ba\&utm_source=Coronavirus+Update+-

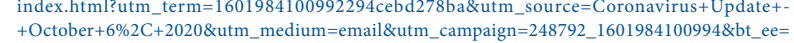
+October+6\%2C+2020\&utm_medium=email\&utm_campaign=248792_1601984100994\&bt_ee=
kCBwaQNPCgkYS8XD9DNxaqoUztjZ5laa7KQ2gLw50ggo2VmOxB0ULt5MrXRwb4\%2F\&bt_ ts=1601984100994 (accessed 7 October 2020)

4. Howard J, Mascarenhas L. To treat Covid-19, President Trump is taking remdesivir, dexamethasone and more. CNN Health, 5 October 2020. https://edition.cnn.com/2020/10/04/health/covid-trumpdrugs-remdesivir-dexamethasone-explainer/index.html (accessed 7 October 2020).

S Afr Med J 2020;110(12):1156-1157. https://doi.org/10.7196/SAMJ.2020.v110i12.15362 